\title{
SURFACE SEGREGATION FROM GOLD ALLOYS
}

\author{
Peter A. Dowben, Allen H. Miller and Richard W. Vook \\ Department of Physics and the Laboratory for Solid State Science and Technology, \\ Syracuse University, Syracuse, NY 13244, USA
}

\begin{abstract}
Among the properties of alloys affected by surface segregation are corrosion resistance and strength. In this paper, the surface segregation phenomenon is reviewed, with particular attention given to gold-containing alloys. A brief discussion of the various thermodynamic models for surface segregation is provided. The results of experimental investigations of surface segregation for gold-containing alloys are summarized and explained in terms of some of the thermodynamic models.
\end{abstract}

\section{Introduction}

Surface segregation is the enrichment at the surface or surface region of one component of an alloy as a result of diffusion of that element from the bulk to the surface region. The driving force for segregation is the difference in the chemical potential between the surface and the bulk for a given component. When equilibrium is reached, minimization of the total free energy (including contributions from the bulk and the surface region) at a given temperature may result in some surface segregation so that thermodynamic equilibrium is achieved. The amount of segregation enrichment will depend upon the equilibrium temperature and on the concentration of the components in the bulk alloy.

The presence of impurities at the surface either as a result of diffusion from the bulk or adsorption from the ambient background can also influence the equilibrium segregation. Even with the advent of ultra-high vacuum (UHV) of $10^{-10}$ Torr or less, and the increasing availability of surface sensitive characterization probes such as Auger electron spectroscopy (AES) and photoelectron spectroscopies (XPS, UPS and ESCA), the investigation of surface segregation remains a difficult task.

The appeal of gold alloys as a means of studying segregation is twofold. First, scrupulous cleaning of the surface of noble metal alloys is fairly easy to accomplish; thus, gold alloy surfaces are usually better characterized than those of most other alloys. Secondly, typical gold alloys such as $\mathrm{Au}-$ $\mathrm{Pd}, \mathrm{Au}-\mathrm{Ag}, \mathrm{Au}-\mathrm{Cu}$, and $\mathrm{Au}-\mathrm{Pt}$ have very low sticking coeffi- cients for the adsorption of $\mathrm{CO}, \mathrm{O}_{2}, \mathrm{~N}_{2}, \mathrm{CO}_{2}$ and $\mathrm{CH}_{4}$. As a result of these low sticking coefficients, the gold alloy surfaces do not rapidly acquire significant amounts of contamination. Following cleaning, the surfaces of gold alloys remain free of impurities for longer than do the surfaces of many other alloys. For these reasons, the studies of surface segregation for gold alloys are, in general, more reliable and better characterized than for other alloys.

Despite the difficulties in the investigation of segregation - and there are many - there is considerable interest in this phenomenon. Affected by it are such properties as the corrosion resistance, the strength and the catalytic properties of alloys. There have been a number of recent reviews focusing on different aspects of the segregation phenomenon (1-10). This review examines the segregation occurring at the surfaces of miscible alloys containing gold.

\section{Thermodynamics of Segregation}

Segregation is a manifestation of thermal and chemical equilibrium. Calculations of the strength of segregation can be attempted with simple models or models that are singularly complex. The complexities may arise from an inability to assess accurately specific parameters such as bond strength enthalpies. Nonetheless, there are a number of different approaches for constructing a model of surface segregation, though none is without flaws. These statistical thermodynamic calculations have sometimes applied simplified models to segregation with considerable success. While a brief outline and comparison of some of these ap- 
proaches will be given in Sections $2.2-2.5$, detailed explanations of the calculations should be sought in the original references. In general, the phenomenological description of free surface segregation is similar to that for adsorption at surfaces or interface segregation.

\subsection{The Phenomenological Model of McLean}

One of the simplest segregation models is that of McLean $(9,11,12)$, applied originally to solute segregation at grain boundaries, but also applicable to segregation at free surfaces. If the amount of segregation at the surface (only the topmost layer) is $\theta$, denoted in fractions of a monolayer, then

$$
\theta /(1-\theta)=\chi \exp \left(-\Delta E_{\text {seg }} / k T\right)
$$

For a binary alloy with components $\mathrm{A}$ and $\mathrm{B}, \theta$ is the surface layer concentration of component $\mathrm{B}$, and $\chi=\chi_{B}^{b} /\left(1-\chi_{B}^{b}\right)$, where $\chi_{A}^{b}$ and $\chi_{B}^{b}$ denote the bulk concentrations of $\mathrm{A}$ and $\mathrm{B}$ respectively. The heat of segregation, $\Delta E_{\text {seg }}$, is the system energy change when an atom of type B originally in the bulk changes position with an A atom originally at the surface (see Figure 1). The sites are tacitly assumed to have equivalent environments. Positive (negative) values of $\Delta E_{\text {seg }}$ correspond to enrichment of $\mathrm{A}$ (B) at the surface. Only the top layer is allowed enrichment; in other words, in this model the selvedge (surface region) is assumed to be like the bulk and is ignored.

The segregation enthalpy $\Delta H_{\text {seg }}$ and entropy $\Delta S_{\text {seg }}$ are related to $\Delta E_{\text {seg }}$ by

$$
\Delta E_{\text {seg }}=\Delta H_{\text {seg }}-T \Delta S_{\text {seg }}
$$

neglecting configurational entropy terms.

\subsection{The Bond-Breaking Models - Effects of Bond Energy Differences}

Williams and Nason (13) constructed the first microscopic theory for binary alloy surface compositions, allowing for the non-equivalence of different sites at the surface and in the bulk. The total crystal energy is assumed to be the sum of pair-bond energies between first and second nearest neighbours. The concentrations of the first four layers are determined by minimizing the total free energy of the crystal while the remaining layers are set at the bulk concentration. For each layer, the two components of the binary alloy are assumed to randomly occupy the lattice sites.

The ideal solution is formally defined by the assumption that $\epsilon_{A B}=1 / 2\left(\epsilon_{A A}+\epsilon_{B B}\right)$ where $\epsilon_{A A}, \epsilon_{B B}$, and $\epsilon_{A B}$ are the pair-bond enthalpies for the $\mathrm{A}-\mathrm{A}, \mathrm{B}-\mathrm{B}$, and $\mathrm{A}-\mathrm{B}$ bonds, respectively. These enthalpies are negative quantities. There is also assumed to be no heat of mixing. Assuming ideality and considering nearest-neighbour bonds only, the result of this model is that only the top layer composition differs from that of the bulk, with

$$
\chi_{B} / \chi_{A}=\left(\chi_{B}^{b} / \chi_{A}^{b}\right) \exp \left(-\Delta E_{\epsilon} / k T\right)
$$

giving the surface layer compositions $\chi_{A}$ and $\chi_{B}=1-\chi_{A}$ of the components $\mathrm{A}$ and $\mathrm{B}$, respectively. The heat of segregation in this model is

$$
\Delta E_{\epsilon}=\left(\epsilon_{A A}-\epsilon_{B B}\right) Z_{v} / 2
$$

where $Z_{\nu}$ is the number of first nearest-neighbours of a lattice site from the layer directly below (towards the bulk).

It is worth noting that Equations 3 and 4 are formally equivalent to the Langmuir-McLean isotherm (Equation 1). This can be seen easily by rewriting Equation 1 so that it gives the surface layer composition ratio $\chi_{B} / \chi_{A}$ (note that $\theta=\chi_{B}$ ). The result is precisely Equation 3 if $\Delta E_{\text {seg }}$ is replaced by $\Delta E_{\epsilon}$. Hence the microscopic theory recovers the phenomenological results; the equivalent-site assumption in the latter is formally equivalent to assuming ideality in the former.

$$
\begin{aligned}
& \text { If } \epsilon_{A A}>\epsilon_{B B} \text {, then } \chi_{B} \rightarrow \chi_{B}^{b} \text { if }\left(\Delta E_{s e g} / k T\right) \rightarrow 0, \\
& \text { but } \chi_{B} \rightarrow 0 \text { as }\left(\Delta E_{s e g} / k T\right) \rightarrow \infty .
\end{aligned}
$$

Thus, the component with the smaller size pair-bond enthalpy (component A) is enriched at the surface. For a fixed number of $\mathrm{A}$ atoms in the crystal, we can reduce the energy by enriching the surface layer with $A$ atoms; thus more $B$ atoms are placed in the bulk, where there are no 'broken bonds'. This is energetically favourable as B atoms have bond strengths with their neighbours greater in magnitude than is the case for A atoms. We can see that 'broken bonds' are important in driving segregation from an inspection of the $Z_{v}$ factor in Equation 4. The $Z_{v}$ factor is the number of missing pair-bonds of a surface atom.

Values of the pair-bond enthalpies $\epsilon_{A A}$ and $\epsilon_{B B}$ are obtainable from pure component heats of vaporization, since $Z \epsilon_{A A_{\mathrm{B} B B}} / 2$ gives the heat of vaporization of components $A$ and $B$ in a model in which first nearest neighbour bonding dominates, with $Z$ as the number of first neighbours of a bulk site.

An improvement in the ideal solution model allows for surface bond relaxation - the change in the bond strength at the surface due to the interfacial discontinuity. Assuming that the bond strengths at the surface are greater than is the case in the bulk, it is found (13) that the top (surface) layer enrichment is diminished, and also that the second layer is now enriched by the component opposite to that of the top layer. 
A further improvement to the microscopic model of segregation can be made by adopting the regular solution model. This theory generalizes the ideal solution model. The regular solution model permits energy mixing. The mixing energy $2 \Omega$ is defined by

$$
\Omega=\epsilon_{A B}-1 / 2\left(\epsilon_{A A}+\epsilon_{B B}\right)
$$

While the mixing energy is non-zero, it is assumed to be independent of the bulk concentration.

For a clustering alloy, $\Omega>0$ and so the unlike-pair bond strength is less than the like-pair bond strength average. There is then a greater proportion of like-atom first nearest neighbours than would occur if the distribution were random, in both the surface normal direction and the crystal layer planes parallel with the surface. For an ordering alloy, $\Omega<0$ and a greater proportion of unlike atoms are first nearest neighbours than would be the case if the distribution were random.

Non-ideality results in a composition profile (13), i.e. a changing segregation concentration from the surface to the bulk, not necessarily limited to the surface. This means that segregation is not limited to the first two layers but penetrates into the selvedge. This is true even if only the first nearest neighbour interactions are included. For values of the parameters usually employed in these calculations, segregation is typically negligible beyond the third or fourth layer from the surface.

For clustering alloys, the non-ideality generally yields a monotonic concentration profile of one component from the surface to the bulk, omitting surface bond relaxation from the model. In other words, the concentration in each successive layer from the surface to the bulk has a reduced enrichment, with the enrichment always from the same component.

An oscillatory concentration profile is generally found for ordering alloys, i.e. the enriched component alternates with each layer. The oscillation in concentration of the segregating element is a result of a preference for $A-B$ bonds represented by $\Omega<0$. A large positive value of $\Delta E_{\text {seg, }}$, for example, drives the segregation of $A$ to the surface, resulting in a large concentration of $A$ at the surface. The second layer thereby becomes enriched in $\mathbf{B}$.

Other calculations using broken-bond models for segregation (14-25) allow for non-random distributions within a single layer. These later models treat surface bond relaxation more precisely, and methods other than segregation experiments are developed to extract bond enthalpy parameters from empirical data.

\subsection{The Effect of Differences in the Atomic Size at the} Surface on Segregation.

Not only is it favourable to have atoms occupying surface positions which have the lowest bond energies, as discussed above, but it is also favourable for the atoms with the largest atomic radii to be located at the surface. In order to see the importance of having large surface-area atoms at the surface, note that an increase in the proportion of large atoms at the surface layer results in an increase in the surface lattice parameters. This reduces the total number of surface atoms required to populate the surface layer. Since the total number of atoms of each component of an alloy is fixed, placing the larger atoms at the surface reduces the (algebraic) increase in energy due to broken bonds at the surface.

This effect can be incorporated $(2,10,26,27)$ into the broken-bond models by replacing $\Delta E_{\epsilon}$ in Equation 4 with $\Delta E_{\gamma}$, defined by

$$
\Delta E_{\gamma}=\left(\gamma_{A}-\gamma_{B}\right) a_{A B}
$$

where the parameters $\gamma_{A}$ and $\gamma_{B}$ are the surface tensions of the pure materials $\mathrm{A}$ and $\mathrm{B}$ respectively. The parameter $a_{A B}$ is the effective area of a surface atom (averaged over the two components, weighted by their surface layer compositions).

From Equation 6, it is clear that the component with the smaller surface tension segregates to the surface, enriching the surface layer. Using the parameter $\gamma_{A}-\gamma_{B}$ in establishing the driving force for segregation takes into account two important factors. First, the atoms that are most loosely bound to like atoms are more energetically favourable for segregation to the surface; second, the large surface-area atoms are also favoured to populate the surface. Both effects relate directly to the missing bonds at the surface layer.

\subsection{The Effect of Elastic Strain}

Another important consequence of the atomic size differences of the different components of an alloy are the bulk strain effects. The immediately preceding discussion concerned only the atomic area effect for atoms residing at the surface. A mismatch of atomic sizes in a binary alloy will give rise to an elastic strain field, and an associated strain energy in the bulk of a crystal as well.

The special case of a dilute binary alloy is perhaps the easiest example to take for assessing the effect of elastic strain energy and strain field upon surface segregation (note that $\Delta E_{\epsilon}$ can now be either positive or negative, and the same is true for $\Delta E_{\gamma}$ ). Let the solute component be labelled $\mathrm{A}$, with the solvent component denoted as $\mathrm{B}$. If a solute atom originally in the interior is transferred to the surface, there is a relief of lattice strain in the bulk. The 
transfer will introduce lattice strain at the surface; however, the smaller number of atoms surrounding a 'mismatched' atom at the surface means that this energy increase does not completely compensate the energy loss due to the relief of bulk strain. Thus, lattice strain effects tend to encourage solute segregation $(12,26,28)$. This means that the exchange of a solute atom in the bulk with a surface solvent atom reduces the system energy by the magnitude of $\Delta E_{e l}$, where the negative energy $\Delta E_{e l}$ can be computed by continuum elasticity theory, for example. Such an estimate for $\Delta E_{e l}$ is (29)

$$
\Delta E_{e l}=-(16 / 9) \pi \mu_{B} r_{B}\left(\sigma^{*}-1\right)^{2}
$$

where $\mu_{B}$ is the shear modulus of the pure solvent, $r_{B(A)}$ is the radius of the solvent (solute) atom and $\sigma^{*}$ is the atomic size ratio $r_{A} / r_{B}$. In deriving Equation 7, we have included the fact that the strain relief obtained by removing the mismatched atom from the bulk is partially compensated by the strain induced at the surface by the mismatched atom, according to the formulation of Eshelby (29), derived from linear elasticity theory.

The effects of bond-breaking and elastic strain may be combined by setting the segregation energy $\Delta E_{\text {seg }}$ equal to the sum of the bond-breaking and elastic contributions (2, $26,28)$ given by Equations 6 and 7 :

$$
\Delta E_{\text {seg }}=\Delta E_{\gamma}+\Delta E_{c l}
$$

Equation 8 can be rewritten in the form:

$$
\begin{aligned}
& \Delta E_{\text {seg }} / \epsilon_{B B}=C_{\gamma}\left(\gamma^{*}-1\right)-C_{e l}\left(\sigma^{*}-1\right)^{2} \\
& \text { where } \gamma^{*}=\gamma_{A} / \gamma_{B}, C_{\gamma}=\gamma_{B} a_{A B} / \epsilon_{B B}, \text { and } \\
& C_{e l}=(16 / 9) \pi \mu_{B} r_{B} / \epsilon_{B B} .
\end{aligned}
$$

In Equation 9, $\Delta E_{\text {seg }}$ is primarily determined by the relative parameters $\gamma^{*}$ and $\sigma^{*}$, i.e. the ratios of surface tensions and atomic radii for the two components.

The discussion in Sections 2.3 and 2.4 is close (but not identical) to that of Abraham, et al. $(2,27,28)$, and is applicable to dilute alloys only. Recently, van Langeveld (30) has extended the analysis to alloys in general and has given a detailed analysis of the effects of non-ideality. Miedema $(31,32)$ has presented a theory for predicting the segregating component in a dilute alloy. The spirit of this theory is similar to that of Abraham et al. $(2,27,28)$, which has also achieved substantial success. An overview of this theory is given by Chelikowsky (33).

\subsection{Electronic Models}

Recently there have appeared models which combine, in a single unified formalism, the two contributions of broken bonds at the surface and elastic strain in the bulk upon the surface segregation $(22,26,34-41)$.

Some of these models $(2,35)$ can be called pair-potential approximation models. For these models, the total energy is written as a sum over pairwise interactions. This summation over pairwise interactions permits these models to share some similarity with the 'broken-bond' models. Nonetheless, there is a distinct difference - these pair-potential approximation models calculate the energy of pairwise interactions as a function of the atomic separation. In the pair-potential approximation models, the atoms are allowed to move to their equilibrium positions and the strain energy is included naturally.

A difficulty in the pair-potential approach is that of accounting for the energy of the background electron gas of the metal. In some of the pair-potential models (35), this problem is corrected by adding a term to the energy which depends on the average atomic volume. This approach, however, is semi-phenomenological. There is no clear way to determine how this additional energy term depends on the average atomic volume and the various bulk alloy compositions.

Several attempts have been made to construct electronic models for surface segregation that avoid a semiphenomenological energy term. All of these models require additional testing. We shall examine one of the models, introduced by Foiles (42), to indicate the spirit of the electronic models for surface segregation. The approach uses the embedded-atom technique $(43,44)$. The total electron density in the vicinity of a given atom is considered to be the atomic density of the atom in question, plus an electronic density from the surrounding atoms. The latter contribution to the total electron density varies slowly with position and the value of this contribution can be set approximately by using the magnitude of the electron density from surrounding atoms at the center of the 'embedded' atom. There is also an additional electrostatic energy contribution from the core-to-core overlap of neighbouring atoms. The total energy is written (42) approximately as:

$$
E_{T O T}=\Sigma F_{i}\left(\rho_{i}\right)+(1 / 2) \Sigma_{i} \Sigma_{j \neq i} \phi_{i j}\left(R_{i j}\right)
$$

where $\rho_{i}$ is the electron density at atom $i$ due to the surrounding atoms in the system and $F_{i}\left(\rho_{i}\right)$ is the energy needed to embed atom $i$ into the electron density $\rho_{i}$. The factor $\phi_{i j}\left(R_{i j}\right)$ is the core-to-core pair repulsion between atoms $i$ and $j$ separated by the distance $R_{i j .}$. The electron density is approximated by the superposition of atomic densities

$$
\rho_{i}=\Sigma_{j \neq i} \rho_{j}\left(R_{i j}\right)
$$


where $\rho_{j}(R)$ is the atomic electron density due to atom $j$, and is taken from Hartree-Fock calculations.

The embedding function $F(\rho)$ is extracted from expressions derived in embedded-atom theory $(43,44)$ and provides a sublimation energy for the metal as a function of the lattice constant (45). The pair repulsion is chosen to be a Yukawa potential. The free energy corresponding to Equation 10 has been minimized by Monte Carlo simulation techniques by varying composition arrangements of the atoms and their atomic positions. By changing atomic positions in deriving the minimum free energy, the lattice strain effects are included naturally in this electronic model. This embedded-atom model has been used to calculate the heat of segregation in the dilute limit as well as the composition profiles from the surface to the bulk for Ni-Cu alloys. The model does appear to provide a satisfactory description of what occurs in Ni-Cu alloys.

\section{Segregation Kinetics}

Diffusion to and from the surface, neglecting the surface chemical potential and attendant heat of segregation, is governed by Fick's second law. The dependence of the concentration on depth into the crystal must therefore be a solution of

$$
\frac{d C(x, t)}{d t}=\frac{D d^{2} C(x, t)}{d x^{2}}
$$

where $C(x, t)$ is the concentration per unit volume of the element enriched at the surface as a function of distance into the bulk $x$ and time $t$. Solving this differential equation gives us

$$
C(x, t)=\left(\alpha /(\pi D t)^{1 / 2}\right) \exp \left(-x^{2} / 4 D t\right)
$$

where $\alpha$ is the concentration of the desegregating element at $t=0$ and $D$ is the diffusion coefficient $(12,46)$.

Segregation, however, does have a heat of segregation driving the diffusion. Assuming a constant enrichment ratio $\beta$ for the segregating element of concentration $\theta$ at the surface, to the concentration of the next layer adjacent to it $X_{c}(d)$, then for a short period of time $t$ :

$$
\frac{\theta(t)-\theta(0)}{\theta(\infty)-\theta(0)} \simeq(2 / d)(2 D t / \pi)^{1 / 2}
$$

where $d$ is the thickness of the boundary and $D$ is the diffusion coefficient (1). The rate of segregation is:

$$
d \theta / d t=\nu \chi \exp \left(-E_{d i f f} / k T\right)
$$

where $\nu \chi$ is the pre-exponential function (dependent on the diffusivity and concentration of the segregating element) and $E_{\text {diff }}$ (see Figure 1) is approximately the activation barrier to diffusion. By measuring the segregation rate at two different temperatures, but at the identical surface segregation concentration $\theta$, we obtain

$$
\begin{aligned}
& R_{1}=d \theta / d t=\nu \chi \exp \left(-E_{d i f f} / k T_{1}\right) \\
& R_{2}=d \theta / d t=\nu \chi \exp \left(-E_{d i f f} / k T_{2}\right)
\end{aligned}
$$

and

$$
\ln \left(R_{2} / R_{1}\right) k\left(1 / T_{1}-1 / T_{2}\right)^{-1}=E_{\text {diff }}
$$

providing the activation barrier to segregation.

Extensions of the McLean theory of the kinetics of segregation (47-50) have been given by several authors. In the extension by Willie and Vennick (50), a composition profile is derived, in addition to obtaining the surface composition, as a function of time.

\section{Preparation of Gold Alloy Surfaces}

The ability to clean gold alloy surfaces using present ultrahigh vacuum (UHV) technology makes these alloys attractive to surface scientists, in particular to researchers interested in surface segregation. There are a number of problems associated with cleaning an alloy surface. The major problems include:

- assessing when the surface of the sample is indeed clean and free of impurities, since contaminants like oxygen (51), carbon monoxide (52) and other gases (53) will alter surface compositions;

- removing defects in the surface that result from the cleaning procedure (in particular, procedures that include ion bombardment) and

- depleting one of the constituents of the alloy as a result of preferential ion bombardment sputtering efficiencies. While all these problems are common to any investigation of surface segregation, the preferential sputtering of one element in gold-containing alloys is a persistent problem $(26,54-66)$.

Some studies of gold-containing alloys have avoided the problems associated with cleaning the surface of the alloy. Some experimentalists have mechanically cleaned the surface using such techniques as scribing their alloy surface, i.e. mechanically making a scratch in the surface (54) to expose bare metal, or by fracturing the sample $(67,68)$. An alternative method for avoiding the problems associated with cleaning a gold alloy has been to make the alloy in the UHV conditions by metal effusion and deposition on a mica substrate, thus effectively making a new surface (55, $61,69,70,72$ ). Both these methods, however, may leave the surface with a number of defects or in a condition that does not represent either thermodynamic or chemical equilibrium. 


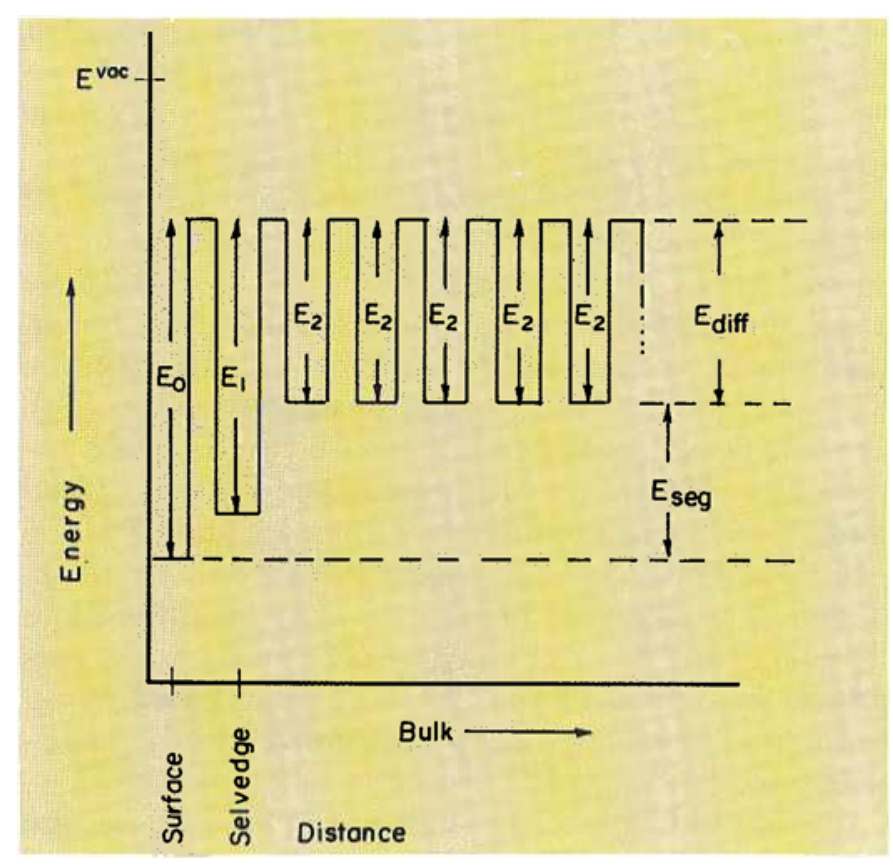

Fig.1 A schematic representation of the energies in surface segregation. $E_{0}, E_{1}, E_{2}$ represent the potential well of an atom at the surface, selvedge, and bulk respectively. $\Delta E_{\text {diff }}$ is the energy barrier for diffusion; $\Delta E_{\text {seg }}$ is the energy of segregation.
Most alloys containing gold that have been used in surface segregation studies were prepared by melting the constituent metals together $(26,54,56-57,62-63,67-68,73-77)$, polishing, typically using diamond or alumina grit down to 1 $\mu \mathrm{m}$ grit size or less $(51,54,56,57,77,78)$, chemically treating $(74,75,79)$, and annealing $(56,62,63,67,68,73$, $74,76,79)$. Chemical treatments were often combined with the annealing of the gold alloy samples since the samples were not always annealed in just vacuum $(63,73)$, or argon $(62,74,76,77)$, but in hydrogen $(68,75,77,80)$ and oxygen $(79,81)$ as well. Following the preparation of the goldcontaining alloy, the sample is then placed in ultra-high vacuum and further efforts are made to remove the residual contamination from the surface.

The residual contaminants present at gold alloy surfaces during the final stages of cleaning and preparing the sample surface in UHV are outlined in Table I. These residual contaminants, listed in Table I, segregate to the surface from the bulk of the gold alloy. These impurities are removed from the surface using a variety of procedures, typically by annealing the surface and sputtering away the contamination using $\mathrm{Ar}^{+}$ion bombardment (see Table I). These procedures are not as extensive and tedious as the cleaning procedures required for a great many other metal surfaces (82).

\section{Table I \\ Cleaning Procedures for Gold-containing Alloy Surfaces}

\begin{tabular}{|c|c|c|}
\hline Major Surface Contaminants & Alloy & Cleaning Procedures \\
\hline$C(73,81,86), S(73), P(73), C a(73)$ & Pt-Au & $\begin{array}{l}\text { Annealed at } 1000 \mathrm{~K} \text { for } 60 \mathrm{hrs} \text { in } 1 \times 10^{-4} \mathrm{~Pa} \mathrm{O}_{2}(86) \text {; repeated sputter and } \\
1000^{\circ} \mathrm{C} \text { annealing treatments }(63,73)\end{array}$ \\
\hline$S(26,74), C(26)$ & $\mathrm{Ni}-\mathrm{Au}$ & $\begin{array}{l}\text { Annealed at } 900^{\circ} \mathrm{C} \text { and sputtered for } 36 \text { hours (74); annealed in } \mathrm{O}_{2} \text { and } \mathrm{H}_{2} \text {, } \\
\text { then sputtered and annealed (26); high temperature annealing and } \\
\text { sputtering (80) }\end{array}$ \\
\hline $\begin{array}{l}S(62,76), C l(62,76), O(62,76) \\
N(62,76), N(76)\end{array}$ & $\mathrm{Ag}-\mathrm{Au}$ & $\begin{array}{l}\text { Repeated sputtering and } 650^{\circ} \text { to } 700^{\circ} \mathrm{C} \text { annealing treatments }(57) ; 2 \mathrm{KeV} \mathrm{Ar}^{+} \\
\text {ion bombardment and annealed at } 1000 \mathrm{~K}(75) ; 0.7 \mathrm{KeV} \text { bombardment }(76) \text {; } \\
1.5 \mathrm{KeV} \mathrm{Ar}^{+} \text {ion bombardment and annealing at } 400^{\circ} \mathrm{C}(62) \text {, repeated } \\
\text { sputtering and } 400^{\circ} \mathrm{C} \text { annealing treatments (83) }\end{array}$ \\
\hline $\mathrm{C}(77), \mathrm{O}(77)$ & $\mathrm{Sn}-\mathrm{Au}$ & $1.5 \mathrm{KeV} \mathrm{Ar}^{+}$ion bombardment and heated resistively (77) \\
\hline $\mathrm{C}(56), \mathrm{S}(56), \mathrm{P}(56), \mathrm{Cl}(56), \mathrm{O}(56)$ & $\mathrm{Pd}-\mathrm{Au}$ & $\begin{array}{l}\text { Repeated } 1.5 \mathrm{KeV} \mathrm{Ar}^{+} \text {ion bombardment and } 600^{\circ} \mathrm{C} \text { annealing treatments to } \\
\text { remove } \mathrm{C} \text { and } \mathrm{O} \text { from the Au rich alloys }(56) ; 500 \mathrm{eV} \mathrm{Ar}^{+} \text {ion bombardment } \\
\text { (51) }\end{array}$ \\
\hline$S(91)$ & $\mathrm{Cu}-\mathrm{Au}$ & $\begin{array}{l}\text { Annealed for } 2 \text { hours at } 500^{\circ} \mathrm{C} \text { and sputtered using } 4000 \mathrm{eV} \mathrm{Ar}^{+} \text {ions, then } \\
\text { subsequently annealed for } 20 \text { hours at } 500^{\circ} \mathrm{C} \text {, further annealing for } 20 \text { hours } \\
\text { below the critical temperature to order the surface (91); } \mathrm{Ar}^{+} \text {ion } \\
\text { bombardment and anneal }(100) ; 1.5 \mathrm{KeV} \mathrm{Ar}^{+} \text {ion bombardment (99); } 500 \mathrm{eV} \\
\mathrm{Ar}^{+} \text {ion sputtering at } 45^{\circ} \text { incidence and annealed at } 473 \mathrm{~K}(78) \\
1.0 \mathrm{KeV} \mathrm{Xe}\end{array}$ \\
\hline
\end{tabular}




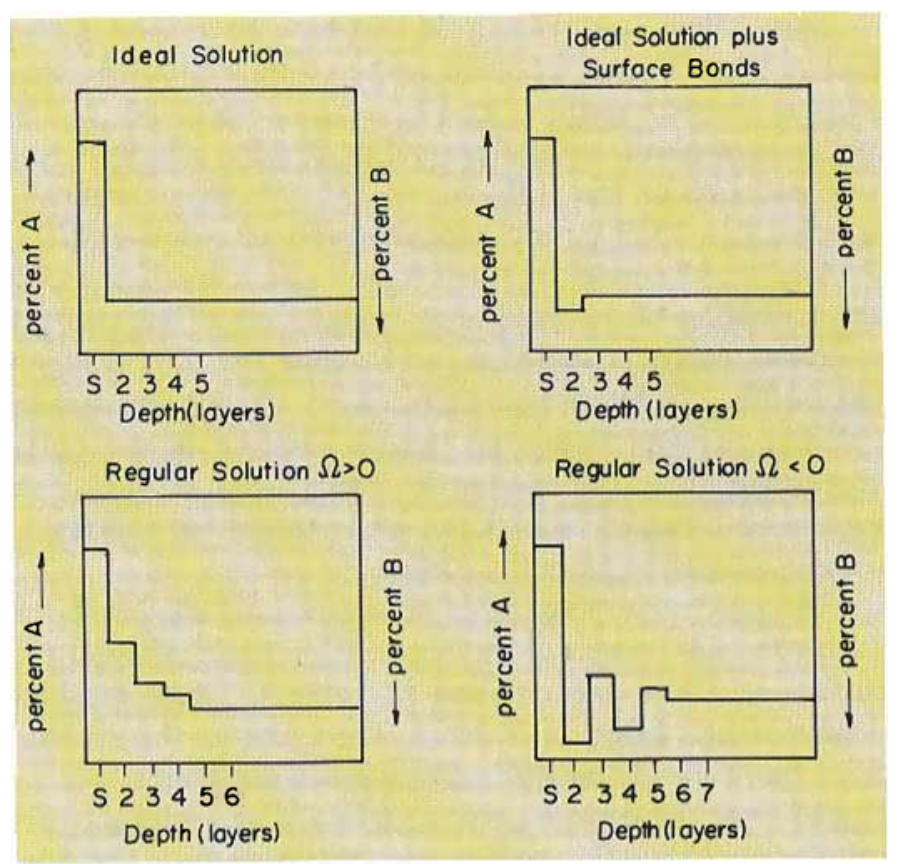

Fig.2 Schenatic representation of the segregation profiles predicted by various theoretical models.

Because preferential sputtering of one of the components of the gold alloy is a common problem, the cleaning procedure alters the surface composition from equilibrium conditions. As a consequence of this problem, lengthy annealing treatments are often undertaken to achieve a surface composition representative of equilibrium. Gold alloy segregation studies carried out without such annealing treatments must be regarded as suspect.

\section{Predicting and Observing Segregation}

As indicated earlier in Section 2, a number of thermodynamic models exist for predicting segregation. There is, however, an empirical model for predicting segregation in dilute alloys, outlined in Sections $2.2-2.4$. This empirical model depends only upon the assessment of two important parameters of the alloy. These are the bond strength ratio $\epsilon^{*}$ (or alternatively the surface tension ratio $\gamma^{*}$ ) and the atomic size ratio $\sigma^{*}$ for the solute atom in the solvent matrix. These parameters are important in predicting segregation because 'ball \& stick' models of segregation reduce the driving force for segregation to the surface bondbreaking and the bulk elastic strain energy (2), as discussed in Sections 2.2 through 2.4 .

Table II lists 12 dilute alloy systems, the segregating component for each alloy, and values for $\epsilon^{*}, \sigma^{*}$ and $\gamma^{*}$.

First, we consider the simple broken-bond/ideal solution model, ignoring atomic size mismatch at the surface and elastic strain (Section 2.2). The component with the lower heat of vaporization segregates to the surface, so that the segregation energy is given by $\Delta E_{\epsilon}$, (Equation 4). Then $\epsilon^{*}>1$ and $\epsilon^{*}<1$ predict solvent and solute segregation, respectively, with $\epsilon^{*}=\epsilon_{A A} / \epsilon_{B B^{*}}$. (Recall that $\mathrm{A}$ is the solute and $\mathrm{B}$ is the solvent. Hence $\Delta E_{\text {seg }}<0$ implies solvent segregation, while $\Delta E_{\mathrm{c} \rho o}>0$ gives solute segregation).

To test this model, the 12 alloys are placed on an $\epsilon^{*}-\sigma^{*}$ graph in Figure 3. The utility of the $\epsilon^{*}-\sigma^{*}$ graph was pointed out by Abraham et al. $(2,27,28)$. For 9 of these alloys, the prediction is sustained. Denoting alloys by solvent (solute), we find that not consistent with the model are the observed enrichment of $\mathrm{Au}$ in $\mathrm{Cu}(\mathrm{Au})$ and $\mathrm{Au}(\mathrm{Cu})$. The remaining inconsistency is for $\mathrm{Au}(\mathrm{Ni})$, for which observations (26) indicate Ni segregation, but not conclusively. Experimental confirmation is needed here. It can be concluded that effects of size mismatch are essential for inclusion in a theory of segregation. The large deviations from unity for $\sigma^{*}$ in $\mathrm{Au}(\mathrm{Ni})$ and $\mathrm{Au}(\mathrm{Cu})$ buttress this conclusion, since these are just the alloys for which theory, ignoring size mismatch, clearly does not predict the segregating element.

Models with only elastic strain effects included can also be tested by examination of Figure 3. Here, broken-bond effects of the type discussed in Sections 2.2 and 2.3 are absent. Then, $\Delta E_{e l}$, given in Equation 7 is the only contributor to the segregation energy $\Delta E_{s e g}$. Since $\Delta E_{e l}$ is always negative, solute segregation is always predicted. Inspection of Figure 1 shows that 3 of the 12 alloys are inconsistent with this prediction, as they show solvent segregation.

There are, then, clear inconsistencies with data for a theory with only energy-bond effects or a theory with only elastic strain effects. Examination of a third model - that for which both types of broken-bond effects are included (energy-bond and size mismatch at the surface) provides better results. The segregation energy $\Delta E_{s e g}$ is given by $\Delta E_{\gamma}$ (Equation 6). $\gamma^{*}>1$ predicts solvent segregation, while $\gamma^{*}<1$ predicts solute segregation, with $\gamma^{*}$ as the surface tension ratio $\gamma_{A} / \gamma_{B}$. Elastic strain is absent from the model.

In Figure 4, the 12 alloys are placed on a $\gamma^{*}-\sigma^{*}$ plot. The model predicts solvent segregation (solid dots) above the $\gamma^{*}=1$ line and solute segregation (open dots) below it. This is confirmed in the data distribution in the figure for 11 of the alloys. The one exception, $\mathrm{Au}(\mathrm{Ni})$, is the case where the experimental evidence of nickel segregation is not conclusive.

It is seen that $\Delta E_{\gamma}$, in Equation 6, is a better description of the segregation energy than $\Delta E$, in Equation 4. The success of $\Delta E_{\gamma}$ is due to the fact that $\Delta E$ incorporates size mismatch effects at the surface, while $\Delta E_{\epsilon}$ does not. It should be noted, however, that $\mathrm{Au}(\mathrm{Ni})$ has the largest value of $\gamma^{*}$ of the 12 alloys and therefore Equation 6 predicts that its segregation energy should be large, with Au strongly driven to the surface. The report of nickel segregation in $\mathrm{Au}(\mathrm{Ni})(26)$ is discouraging 


\section{Table II \\ Alloy Parameters for Twelve Gold-containing Alloys}

\begin{tabular}{|c|c|c|c|c|}
\hline Solvent (gold solute) & $\begin{array}{l}\text { Bond strength } \\
\text { ratio } \epsilon^{\star}\end{array}$ & $\begin{array}{l}\text { Atomic size } \\
\text { ratio } \sigma^{\star}\end{array}$ & $\begin{array}{l}\text { Surface tension } \\
\text { ratio } \gamma^{\star}\end{array}$ & $\begin{array}{l}\text { Segregating } \\
\text { component }\end{array}$ \\
\hline $\begin{array}{l}\mathrm{Ag} \\
\mathrm{Cu} \\
\mathrm{Ni} \\
\mathrm{Pd} \\
\mathrm{Pt}\end{array}$ & $\begin{array}{l}1.29 \\
1.09 \\
0.86 \\
0.93 \\
0.66\end{array}$ & $\begin{array}{r}>1.0 \\
1.13 \\
1.16 \\
1.05 \\
1.04\end{array}$ & $\begin{array}{l}1.27 \\
0.88 \\
0.64 \\
0.76 \\
0.63\end{array}$ & $\begin{array}{l}\mathrm{Ag} \\
\mathrm{Au} \\
\mathrm{Au} \\
\mathrm{Au} \\
\mathrm{Au}\end{array}$ \\
\hline \multicolumn{5}{|l|}{ Solute (gold solvent) } \\
\hline $\begin{array}{l}\mathrm{Ag} \\
\mathrm{Ca} \\
\mathrm{Cu} \\
\text { In } \\
\mathrm{Ni} \\
\mathrm{Pd} \\
\mathrm{Sn}\end{array}$ & $\begin{array}{l}0.78 \\
0.48 \\
0.92 \\
0.65 \\
1.16 \\
1.08 \\
0.82\end{array}$ & $\begin{array}{r}<1.0 \\
1.37 \\
0.89 \\
1.13 \\
0.86 \\
0.95 \\
1.17\end{array}$ & $\begin{array}{l}0.79 \\
0.30 \\
1.14 \\
0.49 \\
1.56 \\
1.32 \\
0.48\end{array}$ & $\begin{array}{l}\mathrm{Ag} \\
\mathrm{Ca} \\
\mathrm{Au} \\
\mathrm{In} \\
\mathrm{Ni} \\
\mathrm{Au} \\
\mathrm{Sn}\end{array}$ \\
\hline
\end{tabular}

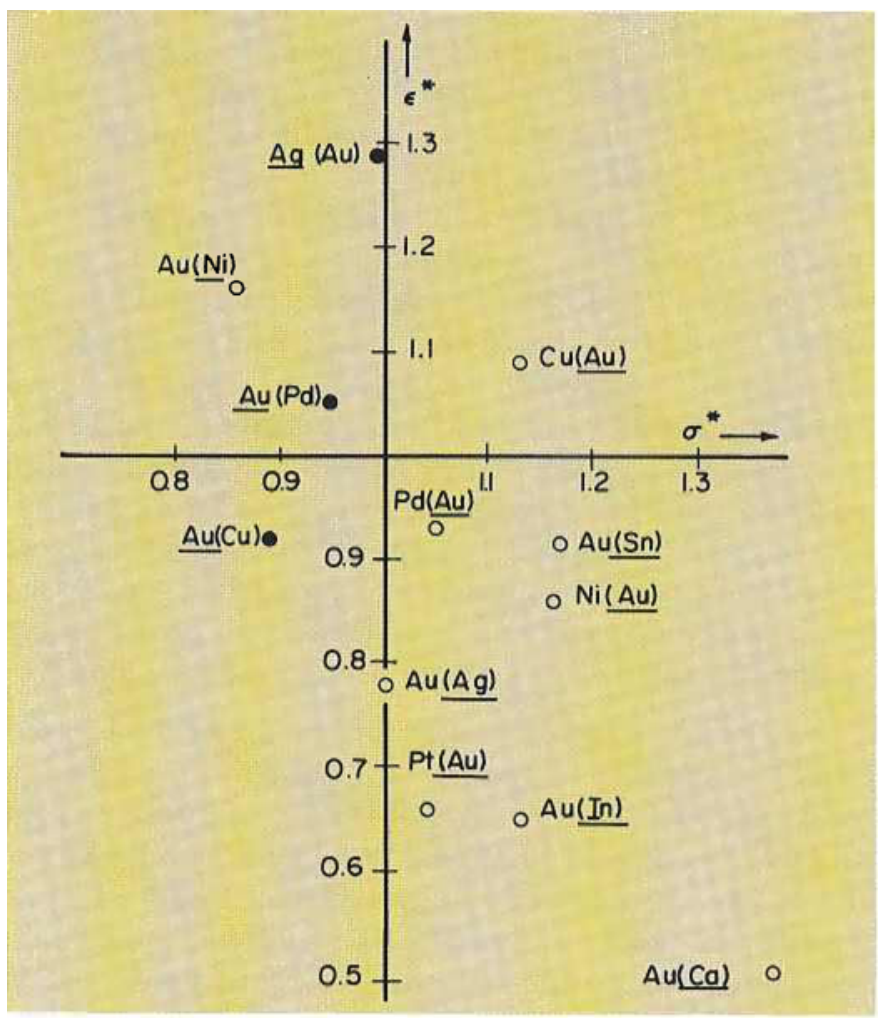

Fig. 3 Distribution of the 12 alloys of Table I, in the $\epsilon^{*}-\sigma^{*}$ plane. The origin is at $(1,1)$. Open and closed circles denote observed surface enrichment of solute and solvent, respectively. The component underlined is the element enriched at the surface. Bond-breaking theory including only effects of bond energy size predicts solvent segregation for $\epsilon^{*}>1$ and solute segregation for $\epsilon^{*}<1$ (i.e., closed circles in the upper two quadrants, open circles in the lower two quadrants). Theories with only elastic strain effects predict solute segregation (open circles everywhere).

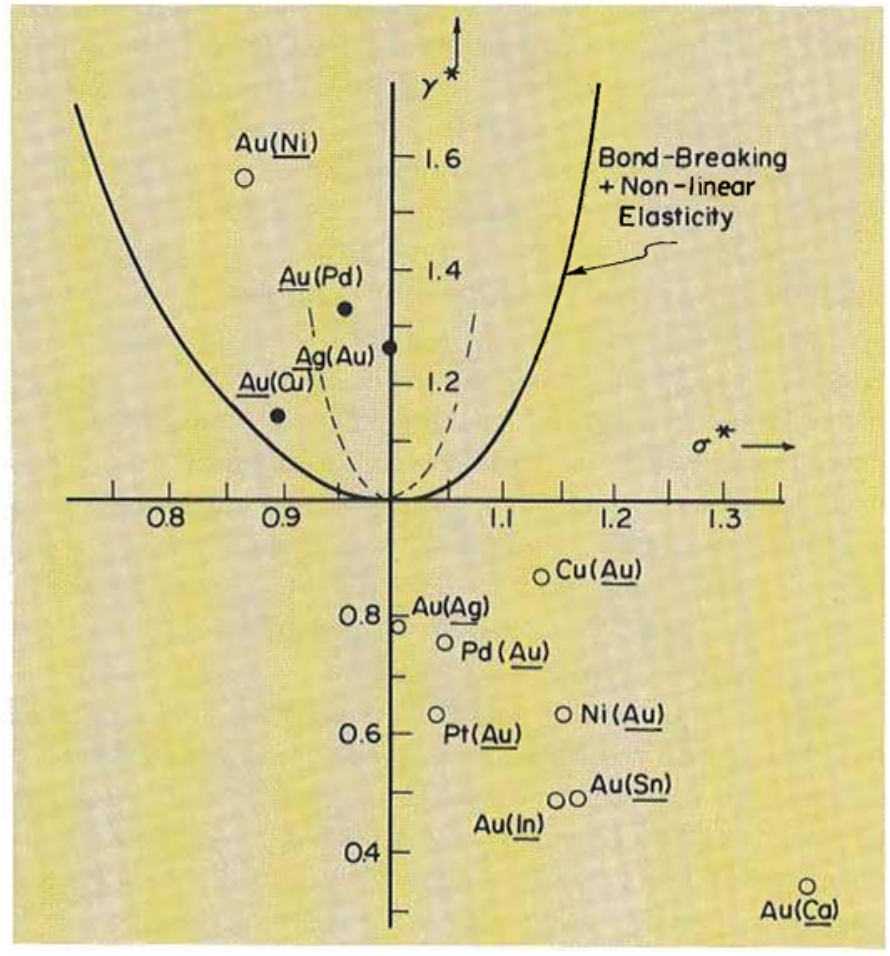

Fig.4 Distribution of the 12 alloys of Table II in the $\gamma^{*}-\sigma^{*}$ plane. Open (closed) circles describe observed surface enrichment for solute (solvent) surface enrichment. The component underlined is the enriched element. Bond-breaking theory (including effects of lattice constant changes at the surface) predicts solvent segregation for $\gamma^{*}>1$ and solute for $\gamma^{*}<1$ (i.e., closed circles in the upper quadrants, and open circles in the lower quadrants). The broken-line curve divides solvent and solute segregation, as predicted by the theory which includes brokenbond effects plus continuum theory elastic strain effects. The solid line is the analogous curve obtained in (2), which also includes non-linear elastic strain effects. 
to any hopes that the simple form $\Delta E_{\gamma}$ represents the segregation energy well. Further (2), the alloy $\mathrm{Zr}(\mathrm{Fe}$ ) shows solute segregation, whereas bond-breaking theory predicts solvent segregation, as $\gamma^{*}=1.22$.

The fourth model which we will compare with empirical data is that of bond-breaking (due to both energy-bond differences and size mismatch at the surface) plus linear elastic strain. The strain energy will be assumed to be given by the continuum elasticity theory result, Equation 7 .

The segregation energy is then given by Equation 9. The boundary between solute and solvent segregation is a parabola in the $\gamma^{*}-\sigma^{*}$ plane defined by $\gamma^{*}-1=D\left(\sigma^{*}-1\right)^{2}$, where $D=C_{e l} / C_{\gamma}$. This ignores a very weak dependence of $D$ on the point $\left(\sigma^{*}, \gamma^{*}\right)$ plane. We have found that, in fact, $D$ typically varies by 1 to 2 per cent over the entire $\sigma^{*}-\gamma^{*}$ plane generated by the 12 alloys of Table II; the largest variation found for $D$ is 3 per cent. Hence, assuming a constant $D$ is quite accurate for our purposes.

In Figure 4, this boundary parabola is drawn as a broken line. The bond-breaking/elastic strain theory predicts solvent segregation (indicated by solid dots) in the interior of the parabola and solute segregation at its exterior. A necessary cautionary point is that the continuum (or linear) elasticity theory is only valid for small deviations of $\sigma^{*}$ from unity. The parabolic shape for the $\Delta E_{e l}$ versus $\sigma^{*}-1$ function is a consequence of assuming that Hooke's law is valid.

How does the combined broken-bond and linear elasticity theory compare with broken-bond theory alone? Inspection of Figure 4 shows that the nickel segregation of $\mathrm{Au}(\mathrm{Ni})$ is now predicted correctly, as it lies outside the parabola (assuming the parabola of demarcation can be extended to values of $\sigma^{*}$ below 0.8 ). This agreement, however, may be completely fortuitous. Linear elasticity theory is unreliable in this region; further, it is seen that the combined broken-bond and linear elasticity theory is worse than broken-bond theory alone in predicting the observed segregation of $\mathrm{Au}$ from $\mathrm{Au}(\mathrm{Cu})$ alloys.

The two alloys for which the prediction is changed, (comparing the combined broken-bond and linear elasticity theory with the broken-bond theory alone), have values of $\sigma^{*}$ equal to $0.86(\mathrm{Au}(\mathrm{Ni}))$ and $0.89(\mathrm{Au}(\mathrm{Cu}))$. Since both values of $\sigma^{*}$ are not within the $\sigma^{*}$ region suitable for valid application of the linear elasticity theory, no conclusion is possible as to whether or not the linear elasticity contribution to broken-bond models improves agreement between prediction and observation.

Finally, we will compare the combined bond-breaking and non-linear elastic theory with experiment. In this case, the solid line in Figure 4 is taken from Abraham, et al. (2, 27,28 ) and gives the boundary between solute and solvent segregation. The curve is obtained by assuming that the atoms lie on a rigid face centered cubic (f.c.c.) lattice, with pair interactions between all pairs of atoms given by the
Lennard-Jones $8: 4$ potential. Points lying on the curve have zero energy change when a solute atom in the bulk is exchanged with an atom on the surface.

Comparison of the curves in Figures 3 and 4 shows an important difference in the results obtained for bondbreaking plus linear elasticity theory versus bond-breaking plus non-linear elasticity theory. For the latter theory, the strain energy for a small solute atom (i.c. $\sigma^{*} \leq 0.95$ ) is much smaller than the strain energy predicted by the bondbreaking plus linear elasticity theory. For this reason, both $\mathrm{Au}(\mathrm{Ni})$ and $\mathrm{Au}(\mathrm{Cu})$ are predicted to have solvent segregation with the non-linear elasticity plus bond-breaking theory. The predictions for the 12 gold-containing alloys are the same as those of the theory invoking bond breaking alone, i.e. $\mathrm{Au}(\mathrm{Ni})$ is the only alloy where theory and experiment disagree.

As noted in (2), however, the prediction for $\mathrm{Zr}(\mathrm{Fe})$ is no longer in disagreement with observation for the non-linear elasticity bond-breaking theory. The observed segregation of $\mathrm{Fe}$ (despite the fact that $\gamma^{*}=1.22$ ) is a failure for bond-breaking theory. The $\gamma^{*}-\sigma^{*}$ point for $\operatorname{Zr}(\mathrm{Fe})$ lies on the boundary curve in the bond-breaking non-linear elasticity theory. It is plausible that improvements in the theory could bring the curve above this point, in harmony with observed solute segregation (2).

While for the most part, the qualitative experimental results for segregation (as summarized in Table III) agree with the simplest of theories, the experimental results for surface segregation of gold-containing alloys are clearly not without controversy. For the $\mathrm{Ag}-\mathrm{Au}(62,69)$ and $\mathrm{Pd}-\mathrm{Au}$ (68) alloys a number of experimental studies indicate that no surface segregation occurs, in contradiction with other experimental data for Ag-Au alloys $(57,75,76,83,84)$, Pd$\mathrm{Au}$ alloys (79), and Pt-Au alloys $(81,85)$ as well as most theoretical models. This absence of segregation may be due to a lack of thermodynamic equilibrium (69) or substantial preferential sputtering of $\mathrm{Au}$ atoms from the surface (68).

Not only has segregation at the surface been observed for gold-containing alloys, but segregation in the selvedge region has been observed as well $(70,76,86)$ for some gold alloys. For most gold alloys, segregation in the selvedge region is neither observed (75) nor predicted $(14,24)$. For example, the theory of Kumar (24) predicts no appreciable segregation beyond the second layer, while the model of King and Donnelly (14) predicts appreciable segregation only up to the second layer and at most an effect only up to the third layer.

The segregation (76), or absence of segregation (75), in $\mathrm{Ag}-\mathrm{Au}$ alloys at the selvedge is a controversy that may be resolved by theory. Selvedge segregation has been observed in $\mathrm{Cu}-\mathrm{Ni}$ alloys $(23,87,88)$ and present theories have not satisfactorily predicted this phenomenon. 
Table III

\section{Experimental Observation of Segregation at Surfaces of Binary Gold Alloys}

\begin{tabular}{|c|c|c|c|c|c|}
\hline $\begin{array}{l}\text { Element Alloyed } \\
\text { with Au: }\end{array}$ & Technique & $\begin{array}{l}\text { Bulk } \\
\text { Temperature }\end{array}$ & $\begin{array}{l}\text { Segregating } \\
\text { Composition }\end{array}$ & $\begin{array}{l}\text { Surface Layer } \\
\text { Component }\end{array}$ & Composition \\
\hline $\mathbf{A g}$ & $\begin{array}{l}\text { ISS } \\
\text { ISS } \\
\text { ISS } \\
\text { ISS } \\
\text { ISS } \\
\text { AES } \\
\text { AES } \\
\text { AES } \\
\text { AES } \\
\text { AES } \\
\text { AES } \\
\text { AES } \\
\text { AES } \\
\text { AES } \\
\text { AES } \\
\text { AES } \\
\text { AES } \\
\text { AES } \\
\text { AES } \\
\text { AES } \\
\text { AES } \\
\text { AES } \\
\text { AES } \\
\text { AES }\end{array}$ & $\begin{array}{l}400^{\circ} \mathrm{C} \\
400^{\circ} \mathrm{C} \\
500^{\circ} \mathrm{C} \\
500^{\circ} \mathrm{C} \\
500^{\circ} \mathrm{C} \\
550^{\circ} \mathrm{C} \\
550^{\circ} \mathrm{C} \\
550^{\circ} \mathrm{C} \\
550^{\circ} \mathrm{C} \\
550{ }^{\circ} \mathrm{C} \\
550-750^{\circ} \mathrm{C} \\
550-750^{\circ} \mathrm{C} \\
650-750^{\circ} \mathrm{C} \\
550^{\circ} \mathrm{C} \\
550^{\circ} \mathrm{C} \\
550^{\circ} \mathrm{C} \\
550^{\circ} \mathrm{C} \\
400^{\circ} \mathrm{C} \\
400^{\circ} \mathrm{C} \\
400^{\circ} \mathrm{C} \\
400^{\circ} \mathrm{C} \\
400^{\circ} \mathrm{C} \\
400^{\circ} \mathrm{C} \\
27^{\circ} \mathrm{C}\end{array}$ & $\begin{array}{l}69.5 \% \mathrm{Ag} \\
55.3 \% \mathrm{Ag} \\
10.4 \% \mathrm{Ag} \\
27.2 \% \mathrm{Ag} \\
64.6 \% \mathrm{Ag} \\
10 \% \mathrm{Aga} \\
10 \% \mathrm{Agb} \\
20 \% \mathrm{Agg} \\
20 \% \mathrm{Agb} \\
30 \% \mathrm{Agc} \\
30 \% \mathrm{Ag}(\mathrm{a}) \\
30 \% \mathrm{Ag} \\
30 \% \mathrm{Ag} \\
10 \% \mathrm{Ag} \\
30 \% \mathrm{Ag} \\
70 \% \mathrm{Ag} \\
90 \% \mathrm{Ag} \\
2 \% \mathrm{Ag} \\
35 \% \mathrm{Ag} \\
50 \% \mathrm{Ag} \\
60 \% \mathrm{Ag} \\
67 \% \mathrm{Ag} \\
85 \% \mathrm{Ag} \\
0.100 \% \mathrm{Ag}\end{array}$ & 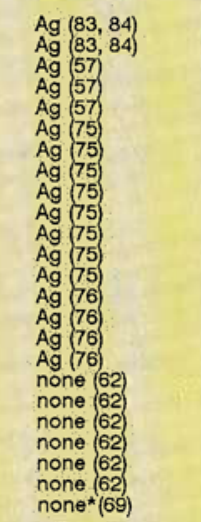 & $\begin{array}{l}84.7 \% \mathrm{Ag} \\
58 \% \mathrm{Ag} \\
30 \% \mathrm{Ag} \\
53 \% \mathrm{Ag} \\
83 \% \mathrm{Ag} \\
37 \% \mathrm{Ag} \\
22 \% \mathrm{Ag} \\
42 \% \mathrm{Ag} \\
31 \% \mathrm{Ag} \\
72 \% \mathrm{Ag} \\
51 \% \mathrm{Ag} \\
40 \% \mathrm{Ag} \\
60 \% \mathrm{Ag} \\
\ldots \\
\therefore \\
\because \\
\because \\
\therefore \\
\therefore \\
\therefore \\
\cdots\end{array}$ \\
\hline $\mathbf{C a}$ & AES & $600 \mathrm{~K}$ & $<<0.01 \% \mathrm{Ca}$ & $\mathrm{Ca}(105)$ & $\cdots$ \\
\hline $\mathrm{Cu}$ & $\begin{array}{l}\text { AES } \\
\text { AES } \\
\text { AES } \\
\text { AES } \\
\text { AES } \\
\text { AES } \\
\text { AES } \\
\text { AES } \\
\text { AES } \\
\text { AES } \\
\text { AES } \\
\text { ISS } \\
\text { ISS } \\
\text { AES } \\
\text { AES } \\
\text { AES } \\
\text { AES } \\
\text { ISS } \\
\text { ISS }\end{array}$ & $\begin{array}{l}400-450^{\circ} \mathrm{C} \\
400-450^{\circ} \mathrm{C} \\
400-450^{\circ} \mathrm{C} \\
400-450^{\circ} \mathrm{C} \\
400-450^{\circ} \mathrm{C} \\
400-450^{\circ} \mathrm{C} \\
400-450^{\circ} \mathrm{C} \\
0-300^{\circ} \mathrm{C} \\
400-500^{\circ} \mathrm{C} \\
6000^{\circ} \mathrm{C} \\
0-600^{\circ} \mathrm{C} \\
0-390^{\circ} \mathrm{C} \\
390-830^{\circ} \mathrm{C} \\
290^{\circ} \mathrm{C} \\
294^{\circ} \mathrm{C} \\
100^{\circ} \mathrm{C} \\
290^{\circ} \mathrm{C} \\
\therefore \\
\therefore\end{array}$ & $\begin{array}{l}29 \% \mathrm{Cu}(\mathrm{b}) \\
41 \% \mathrm{Cu}(\mathrm{b} \\
58 \% \mathrm{Cu}(b) \\
62 \% \mathrm{Cu}(\mathrm{b} \\
72 \% \mathrm{Cu} b \\
80 \% \mathrm{Cu}(\mathrm{b}) \\
87 \% \mathrm{Cu}(b) \\
75 \% \mathrm{Cu} \\
75 \% \mathrm{Cu} \\
75 \% \mathrm{Cu} \\
25 \% \mathrm{Cu} \\
75 \% \mathrm{Cuc} \\
75 \% \mathrm{Cuc} \\
75 \% \mathrm{Cu}(\mathrm{a}, \mathrm{b}, c) \\
50 \% \mathrm{Cu}(\mathrm{a}, \mathrm{b}, c) \\
25 \% \mathrm{Cu}(\mathrm{a}, \mathrm{b}, c) \\
75 \% \mathrm{Cu}(c) \\
43 \% \mathrm{Cu} \\
44 \% \mathrm{Cu}\end{array}$ & 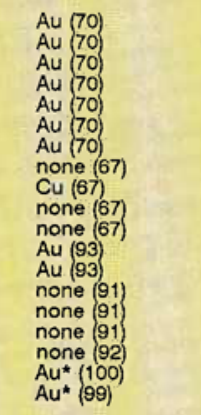 & 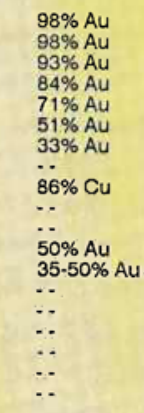 \\
\hline In & AES & $28^{\circ} \mathrm{C}$ & $3 \% \ln$ & $\ln (55)$ & $15 \% \ln$ \\
\hline $\mathrm{Ni}$ & $\begin{array}{l}\text { AES } \\
\text { AES } \\
\text { AES } \\
\text { AES } \\
\text { AES } \\
\text { AES } \\
\text { AES }\end{array}$ & $\begin{array}{l}700^{\circ} \mathrm{C} \\
800-1000^{\circ} \mathrm{C} \\
650-900^{\circ} \mathrm{C} \\
200-810^{\circ} \mathrm{C} \\
232-805^{\circ} \mathrm{C} \\
810-900^{\circ} \mathrm{C} \\
700-1000^{\circ} \mathrm{C}\end{array}$ & $\begin{array}{l}98.5 \% \mathrm{Ni} \\
>99 \% \mathrm{Ni}(\mathrm{b}) \\
0.05 \% \mathrm{Au} \\
5 \% \mathrm{Ni} \\
2 \% \mathrm{Ni} \\
0.1 \% \mathrm{Au} \\
0.005 \% \mathrm{Au}\end{array}$ & $\begin{array}{l}\text { Au }(74) \\
\text { Au }(101,102,104) \\
\text { Au }(26) \\
\text { Ni }(26) \\
\text { Ni }(26) \\
\text { Au }(80) \\
\text { Au }(106)\end{array}$ & $\begin{array}{l}\ldots \\
2-15 \% \\
\therefore \\
\therefore \\
50 \%\end{array}$ \\
\hline Pd & $\begin{array}{l}\text { AES } \\
\text { AES } \\
\text { AES } \\
\text { AES } \\
\text { AES } \\
\text { AES } \\
\text { AES } \\
\text { AES } \\
\text { AES } \\
\text { AES } \\
\text { AES } \\
\text { AES } \\
\text { AES } \\
\text { XPS } \\
\text { ISS }\end{array}$ & $\begin{array}{l}600^{\circ} \mathrm{C} \\
600^{\circ} \mathrm{C} \\
600^{\circ} \mathrm{C} \\
600^{\circ} \mathrm{C} \\
600^{\circ} \mathrm{C} \\
600^{\circ} \mathrm{C} \\
725 \mathrm{~K} \\
725 \mathrm{~K} \\
725 \mathrm{~K} \\
650^{\circ} \mathrm{C} \\
650^{\circ} \mathrm{C} \\
650^{\circ} \mathrm{C} \\
650^{\circ} \mathrm{C} \\
\therefore \\
\therefore\end{array}$ & $\begin{array}{l}1.03 \% \mathrm{Pd} \\
10.4 \% \mathrm{Pd} \\
40.24 \% \mathrm{Pd} \\
69.49 \% \mathrm{Pd} \\
90.1 \% \mathrm{Pd} \\
99.01 \% \mathrm{Pd} \\
40 \% \mathrm{Pd} \\
60 \% \mathrm{Pd} \\
80 \% \mathrm{Pd} \\
12.2 \% \mathrm{Pd} \\
21.2 \% \mathrm{Pd} \\
32.3 \% \mathrm{Pd} \\
42.4 \% \mathrm{Pd} \\
0.100 \% \mathrm{Pd} \\
44.2 \% \mathrm{Pd}\end{array}$ & $\begin{array}{l}\text { Au }(56) \\
\text { Au (56) } \\
\text { Au }(56) \\
\text { Au }(56) \\
\text { Au }(56) \\
\text { Au }(56) \\
\text { none }(79) \\
\text { Au (79) } \\
\text { Au (79) } \\
\text { none } 68) \\
\text { none }(68) \\
\text { none }(68) \\
\text { none } 68 \\
\text { none (51) } \\
\text { Au (51) }\end{array}$ & $\begin{array}{l}99.2 \% \mathrm{Au} \\
93.1 \% \mathrm{Au} \\
70 \% \mathrm{Au} \\
47.6 \% \mathrm{Au} \\
31 \% \mathrm{Au} \\
6.8 \% \mathrm{Au} \\
\because 53 \% \mathrm{Au} \\
27 \% \mathrm{Au} \\
. \\
\because \\
\because \\
\because \\
58 \% \mathrm{Au}\end{array}$ \\
\hline Pt & $\begin{array}{l}\text { XPS binding energies } \\
\text { XPS binding energies } \\
\text { XPS binding energies } \\
\text { SIMS } \\
\text { AES } \\
\text { AES } \\
\text { AES } \\
\text { AES } \\
\text { AES } \\
\text { AP-FIM } \\
\text { AP-FIM }\end{array}$ & $\begin{array}{l}1000 \mathrm{~K} \\
1000 \mathrm{~K} \\
1000 \mathrm{~K} \\
6 \\
500^{\circ} \mathrm{C} \\
25-770^{\circ} \mathrm{C} \\
480-785^{\circ} \mathrm{C} \\
25-800^{\circ} \mathrm{C} \\
600-700^{\circ} \mathrm{C} \\
515^{\circ} \mathrm{C} \\
600^{\circ} \mathrm{C}\end{array}$ & $\begin{array}{l}98 \% \mathrm{Pt} \\
85 \% \mathrm{Pt} \\
10 \% \mathrm{Pt} \\
96 \% \mathrm{Pt} \\
95 \% \mathrm{Pt} \\
10 \% \mathrm{Pt} \\
90 \% \mathrm{Pt} \\
95 \% \mathrm{Pt} \\
5 \% \mathrm{Pt} \\
95 \% \mathrm{Ptb} \\
96 \% \mathrm{Ptb}\end{array}$ & $\begin{array}{l}\mathrm{Au}(86) \\
\mathrm{Au}(86 \\
\mathrm{Au}(86) \\
\mathrm{Au}(85) \\
\mathrm{Au}(63) \\
\mathrm{Au}(72) \\
\mathrm{Au}(72) \\
\mathrm{Au}(72) \\
\mathrm{Au}(73) \\
\mathrm{Au}(103) \\
\mathrm{Au}(85)\end{array}$ & $\begin{array}{l}\ldots \\
100 \% \mathrm{Au} \\
20 \% \mathrm{Au} \\
100 \% \mathrm{Au} \\
99 \% \\
96 \% \mathrm{Au} \\
100 \% \mathrm{Au} \\
\ldots 9 \% \mathrm{Au}\end{array}$ \\
\hline Sn & $\begin{array}{l}\text { AES } \\
\text { AES } \\
\text { AES }\end{array}$ & $\begin{array}{l}150^{\circ} \mathrm{C} \\
150^{\circ} \mathrm{C} \\
150^{\circ} \mathrm{C}\end{array}$ & $\begin{array}{l}50 \% \mathrm{Sn} \\
13.3 \% \mathrm{Sn} \\
1 \% \mathrm{Sn}\end{array}$ & $\begin{array}{l}\text { none (77) } \\
\mathrm{Au}(77) \\
\mathrm{Au}(77)\end{array}$ & $\begin{array}{l}\text { 43\% Au } \\
46 \% \mathrm{Au}\end{array}$ \\
\hline
\end{tabular}

(a) denotes a (110) crystal face; (b) denotes a (111) crystal face; (c) denotes a (100) crystal face.

The techniques used are Auger electron spectroscopy (AES), appearance potential field ion microscopy (AP-FIM), secondary ion mass

spectroscopy (SIMS), ion scattering spectroscopy (ISS or LEIS), and X-ray photoemission spectroscopy (XPS).
$\left({ }^{*}\right)$ indicates that the system studied may not have been at equilibrium. 
For some gold-silver alloys, there is an observed depletion from the second layer of silver (75), while silver segregates to the surface. Since silver is enriched at the first layer, this corresponds to the oscillatory profile expected for ordering alloys (see Section 2.2 and Figure 2 for the regular solution model with $\Omega<0$ ). There exists evidence that Ag-Au alloys are ordered alloys (75), but there is also evidence indicating these alloys are clustering alloys (76) if the regular solution model is used as an indication of their behaviour.

Gold does alloy to form some classic ordered alloys. $\mathrm{Cu}_{3} \mathrm{Au}$ is a particularly good example of an ordered gold alloy. The bulk ordering has been investigated thoroughly $(89,90)$. The long-range bulk order decreases with increasing temperature; and at the critical temperature, the long-range order discontinuously falls to zero, though short-range order is still present $(89,90)$. $\mathrm{Cu}_{3} \mathrm{Au}$ has a negative enthalpy of mixing and a critical ordering temperature of $\mathrm{T}_{\mathrm{c}}=390^{\circ} \mathrm{C}$. While there exist theoretical predictions that, for ordered alloys like $\mathrm{Cu}_{3} \mathrm{Au}$, the ordering and segregation of $\mathrm{Au}$ at the surface inhibit each other (25), and most experimental evidence suggests an absence of segregation in $\mathrm{Cu}_{3} \mathrm{Au}, \mathrm{CuAu}, \mathrm{Au}_{3} \mathrm{Cu}$ alloys $(91,92)$, there also exist recent studies indicating surface segregation. At temperatures both above and below the critical ordering temperature, the $\mathrm{Cu}_{3} \mathrm{Au}(100)$ surface is enriched in gold, corresponding to a composition of $\mathrm{Au}_{0.5} \mathrm{Cu}_{0.5}(78,93-95)$. Below the critical temperature, the second-layer composition is virtually gold-free as expected for an ordering alloy (93, $94,96)$, though very early work suggested otherwise (67, 97). Above the critical temperature, the second layer approaches the average bulk composition with increasing temperature $(93,94,98)$. These results strongly indicate that the composition profile of an ordering alloy critically depends upon the equilibrium temperature and the ordering temperature (which may be very low - less than 600K) for gold-containing alloys. Indeed, Ising model calculations are in good agreement with these segregation observations (16). Other $\mathrm{Cu}-\mathrm{Au}$ alloys exhibit similar composition profiles compared to $\mathrm{Cu}_{3} \mathrm{Au}(99,100)$.

\section{Conclusion}

While in general, surface segregation in gold-containing alloys is modelled well by the current simple theories of segregation, many aspects of surface segregation remain controversial or poorly understood. Some controversy may be an artifact of insufficiently careful preparation of the surface or inadequately established equilibrium. Despite the advantages of gold-containing alloys in their ease of preparation, segregation studies are difficult.

Investigations of segregation in the selvedge are, at present, limited and further work is clearly indicated. Unfortunately, experimental investigation of segregation in the selvedge is usually far more difficult to undertake with care than segregation at the surface (topmost) layer.

The advantages of using gold alloys to investigate segregation are clear. Alloy surfaces of these metal alloys are among the easiest to prepare and preserve in a wellcharacterized condition. Gold alloys exist that exemplify the extremes of ordered or strongly clustering alloys. Finally, despite the cost of the source materials, gold alloys are among the least expensive and simplest alloys to prepare with ultra-high purities as single crystals in well-defined con-centrations.

\section{Acknowledgements}

This work was supported by the Syracuse University Senate and the United States Department of Energy, Basic Energy Sciences Division, on grant no. DE-FG0284ER45139.

\section{References}

1 S. Hofmann, Scanning Electron Microscopy, 1985, pt. 3, 1071

2 F.F. Abraham and C.R. Brundle, J. Vac. Sci. Technol., 1981, 18, 506

3 E.D. Hondros and M.P. Seah, in Physical Metallurgy, 3rd Ed., P. Haasen and R.W. Cahn (eds.), North Holland, Amsterdam, 1983, chap. 13

4 Interfacial Segregation, W.C. Johnson and J.M. Blakely (eds.), Am. Soc. Metals, Metals Park, Ohio, 1979

5 J.M. Blakely, in CRC Critical Reviews in Solid State and Material Sciences, 1978, 7, 333

6 J.M. Blakely and M. Eizenberg, in The Chemical Physics of Solid Surfaces and Heterogeneous Catalysis, 1981, 1, chap. 1

7 M.P. Seah, J. Vac. Sci. Technol., 1980, 17, 16

8 M.P. Seah, J. Phys. F: Metals Phys., 1980, 10, 1043

9 J.M. Blakely and J.C. Shelton, 'Equilibrium Adsorption and Segregation' in Surface Physics of Materials, 1, J.M. Blakely (ed.), Academic Press, 1975, 189-238

10 P. Wynblatt and K.C. Ku, in Interfacial Segregation; W.C. Johnson and J.M. Blakely (eds.), Am. Soc. Metals, Metals Park, Ohio, 1979, 115-136

11 K.I. Rawlings, S.D. Foulias and B.J. Hopkins, Surf. Sci., 1981, 109, 513

12 D. McLean, Grain Boundaries in Metals, Clarendon Press, Oxford, 1957

13 F.L. Williams and D. Nason, Surf. Sci., 1974, 45, 377

14 T.S. King and R.G. Donnelly, Surf. Sci, 1984, 141, 417

15 R.G. Donnelly and T.S. King, Surf. Sci., 1978, 74, 89

16 J.M. Sanchez and J.L. Moran-Lopez, Surf. Sci., 1985, 157, L297

17 V. Kumar and K.H. Bennemann, Phys. Rev. Lett., 1984, 53, 278

18 J.M. Sanchez, F. Ducastelle and D. Gratias, Physica, 1984, 128A, 334 
19 R.A. van Santen and W.M.H. Sachtler, J. Catal., 1974, 33, 202

20 J.L. Moran-Lopez and L.M. Falicov, Phys. Rev., 1978, B18, 2542

21 J.L. Moran-Lopez and L.M. Falicov, Phys. Rev., 1978, B18, 2549

22 L.Z. Mezey and J. Giber, Surf. Sci., 1982, 117, 220

23 U. Vahalia, P. Dowben and A. Miller, J. Vac. Sci. Technol., 1986, A4, 1675

24 V. Kumar, Phys. Rev., 1981, B23, 3756

25 J.L. Moran-Lopez and K.H. Bennemann, Phys. Rev., 1977, B15, 4769

26 P. Wynblatt and R.C. Ku, Surf. Sci., 1977, 65, 511

27 F.F. Abraham, Phys. Rev. Lett., 1981, 46, 546

28 F.F. Abraham, N-H Tsai and G.M. Pound, Surf. Sci., 1979, 83, 406

29 J.D. Eshelby in Progress in Solid Mechanics, II, I.N. Sneddon and R. Hill (eds.), North Holland, Amsterdam, 1961, 89-99

30 A.D. van Langeveld, Thin Solid Films, 1985, 129, 161

31 A.R. Miedema, Z. Metallkd., 1978, 69, 455

32 A.R. Miedema, Philips Tech. Rev., 1976, 36, 217

33 J.R. Chelikowsky, Surf. Sci., 1984, 139, L197

34 D. Tomanek, A.A. Aligia and C.A. Balseiro, Phys. Rev., 1985, B32, 5051

35 P. Wynblatt and D.A. Steigerwald, Surf. Sci., 1985, 150, 289

36 O.L.J. Gijzeman, Surf. Sci., 1985, 150, 1

37 L.Z. Mezey and J. Giber, Surf. Sci., 1985, 162, 514

38 Y.W. Lee and H.J. Aaronson, Surf. Sci., 1980, 95, 227

39 H. Yamauchi, J. Vac. Sci. Technol. . 1981, 18, 506

40 V. Kumar, Surf. Sci., 1979, 84, L231

41 C.A. Balseiro and J.L. Moran-Lopez, Phys. Rev., 1980, B21, 349

42 S.M. Foiles, Phys. Rev., 1985, B32, 7685

43 M.S. Daw and M.I. Baskes, Phys. Rev. Lett., 1983, 50, 1285

44 M.S. Daw and M.I. Baskes, Phys. Rev., 1984, B29, 6443

45 J.H. Rose, J.R. Smith, F. Guinea and J. Ferrante, Phys. Rev., 1984, B29, 2963

46 J. Crank, The Mathematics of Diffusion, Oxford University Press, 1956

47 C. Lea and M.P. Seah, Philos. Mag., 1977, 35, 213

48 G. Rowlands and D.P. Woodruff, Philos. Mag., 1979, A40, 459

49 A.D. Brailsford, Surf. Sci., 1980, 94, 387

50 L.T. Willie and J. Vennik, Phys. Status Soli di, 1985, B131, 443

51 P. Varga and G. Hetzendorf, Surf. Sci., 1985, 162, 544

52 R. Bouwman and V.M.H. Sachtler, J. Catal., 1970, 19, 127

53 S.K. Ray and R.K. Lewis, Thin Solid Films, 1985, 131, 197

54 P.H. Holloway, Surf. Sci., 1977, 66, 479

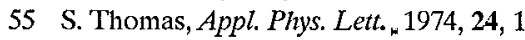

56 A. Jablonski, S.H. Overbury and G.A. Somorjai, Surf. Sci., 1977, 65, 578

57 M.J. Kelley, D.G. Swartzfager and V.S. Sundaram, J. Vac. Sci. Technol., 1979, 16, 664

58 G.C. Nelson, J. Vac. Sci. Technol., 1976, 13, 974

59 G.K. Wehner, in Methods in Surface Analysis, A.W. Czanderna et al. (eds.), Elsevier, New York, 1975

60 J.W. Coburn and E. Kay, CRC Crit. Rev. Solid State Sci., 1974, 4,561

61 P.S. Ho, J.E. Lewis and J.K. Howard, J. Vac. Sci. Technol., 1977, 14,322

62 S.H. Overbury and G.A. Somorjai, Surf. Sci., 1976, 55, 209

63 J.A. Schwarz, R.S. Polizzotti and J.J. Burton, Surf. Sci., 1977, 67,429

64 N. Laegreid and G.K. Wehner, J. Appl. Phys., 1961, 32, 365

65 L.I. Maissel in Physics of Thin Films, 3, G. Haas and R.E. Thun (eds.), Academic Press, New York, 1966, 61
66 R.S. Li, L.X. Tu and Y.Z. Sun, Surf. Sci., 1985, 163, 67

67 R.A. van Santen, L.H. Toneman and R. Bouwman, Surf. Sci., 1975, 47, 64

68 R. Bouwman, L.H. Toneman, M.A. Boersma and R.A. van Santen, Surf. Sci., 1976, 59, 72

69 S.C. Fain and J.M. McDavid, Phys. Rev., 1974, B9, 5099

70 J.M. McDavid and S.C. Fain, Surf. Sci., 1975, 52, 161

71 R.S. Li, T. Koshikawa and G. Goto, Surf. Sci., 1983, 129, 192

72 D. Lamouche, P. Clechet, J.R. Martin, G. Haroutioun and J.P. Sandino, Surf. Sci., 1985, 161, L554

73 J.A. Schwarz, R.S. Polizzotti and J.J. Burton, J. Vac. Sci. Technol., $1977,14,457$

74 W.C. Johnson, N.G. Chavka, R. Ku, J.L. Bomback and P. Wynblatt, J. Vac. Sci. Technol., 1978, 15, 467

75 T.S. King and R.G. Donnelly, Surf. Sci., 1985, 151, 374

76 M. Yabumoto, K. Watanabe and T. Yamashina, Surf. Sci. $1978,77,615$

77 S.H. Overbury and G.A. Somorjai, J. Chem. Phys., 1977, 66, 3181

78 E.G. McRae and R.A. Malic, Surf. Sci., 1984, 148, 551

79 B.J. Wood and H. Wise, Surf. Sci., 1975, 52, 151

80 D.A. Steigerwald, S.J. Miller and P. Wynblatt, Surf. Sci., 1985, 155, 79

81 S.E. Hornström, L.I. Johansson and A. Flodström, Appl. Surf. Sci., 1986, 26, 27

82 R.G. Musket, W. McLean, C.A. Colmenares, D.M.Makowiecki and W.J. Siekhaus, Appl. Surf. Sci., 1983, 10, 143

83 G.C. Nelson, Surf. Sci., 1976, 59, 310

84 G.C. Nelson, J. Vac. Sci. Technol., 1976, 13, 512

85 T.T. Tsong, Y.S. Ng and S.B. McLane, J. Chem. Phys., 1980 73,1464

86 S.E. Hornström, et al., Surf. Sci., 1985, 160, 561

87 P.A. Dowben, Phys. Rev., 1984, B30, 7278

88 U. Vahalia, P.A. Dowben and A. Miller, J. Electron Spectrosc. Rel. Phenom., 1986, 37, 303

89 S.C. Moss, J. Appl. Phys., 1964, 35, 3547

90 J.M. Cowley, J. Appl. Phys., 1950, 21, 24

91 H.C. Potter and J.M. Blakely, J. Vac. Sci. Technol., 1975, 12, 635

92 V.S. Sundaram, R.S. Alben and W.D. Robertson, Surf. Sci., 1974 , 46, 653

93 T.M. Buck, G.H. Wheatley and L. Marchut, Phys. Rev. Lett., 1983, 51,43

94 T.M. Buck, G.H. Wheatley and D.P. Jackson, Nucl. Instr. Methods Phys. Res., 1983, 218, 257

95 K.D. Jamison, D.M. Lind, F.B. Dunning and G.K. Walters, Surf. Sci., 1985, 159, 6451

96 J.M. Sanchez and J.L. Moran-Lopez, Surf. Sci., 1985, 157, L297

97 E. Gillam, J. Phys. Chem. Solids, 1959, 11, 55

98 D. Sondericker, F. Jona and P.M. Marcus, Solid State Commun., $1985, \mathbf{5 3}, 175$

99 R.S. Li, T. Koshikawa and K. Goto, Surf. Sci., 1982, 121, LS61

100 H.J. Kang, R. Shimizu and T. Okutani, Surf. Sci., 1982, 116, L173

101 J.J. Burton, C.R. Helms and R.S. Polizzotti, J. Chem. Phys., 1976, 65, 1089

102 J.J. Burton, C.R. Helms and R.S. Polizzotti, J. Vac. Sci. Technol., 1976, 13, 204

103 Y.S. Ng, T.T. Tsong and S.B. McLane, Surf. Sci., 1979, 84, 31

104 J.J. Burton, C.R. Helms and R.S. Polizzotti, Surf. Sci., 1976, 57, 425

105 S.A. Isa, R.W. Joyner and M.W. Roberts, J. Chem. Soc. Faraday Trans. ., 1976, 72, 540

106 F.L. Williams and M. Boudart, J. Catal., 1973, 30, 438 